J. Neurol. Neurosurg. Psychiat., 1951, 14, 222.

\title{
THE USE OF MARCHI STAINING IN THE LATER STAGES OF HUMAN TRACT DEGENERATION
}

\author{
BY \\ MARION C. SMITH \\ From the Neurological Research Unit of the Medical Research Council, \\ National Hospital, Queen Square, London
}

For the purpose of following tract degenerations the Marchi method, or modifications of this method, have been widely used since its introduction in 1885 .

Disadvantages in its use include the cost, the fact that the nerve terminals are not displayed, and the various hazards in the preparation of the sections, which are not completely eliminated by any of the modifications used in the staining techniques. Nevertheless the fact that the degenerating myelin of the tracts is stained black, and is thus vividly contrasted against the pale brown of the normal myelin, makes it a most useful method for the easy recognition of even small degenerating tracts.

The method has been applied more to experimental animal work than to human tissue, because it has been thought that positive results could be obtained only after recent lesions. It is the purpose of this paper to show that the Marchi method of staining degenerating fibres is of value in human material even when there is a fairly long interval between the occurrence of the lesion and death. The observations made here relate to the central nervous system in human material, and to direct damage of fibre tracts only; no deductions have been drawn as to other pathological human material or to animal work.

It is clear from the literature that most workers using the Marchi technique have considered it of value only where death followed the lesion within a very short time. In animal work, for example, Allen (1923), working with the guinea-pig, states that " according to my experience with the Marchi method, the maximum degeneration appears in mammals about the eleventh day". Kingsbury and Johannsen (1927) state that the optimum time will vary, and must often be determined experimentally. Poljak (1933), using Java and R hesus monkeys, killed his animals 22 to 43 days after the lesion. Swank and Davenport (1934) state that in cats the earliest staining was found at four days, and the maximum at 14 to 20 days. Le Gros Clark (1936), using the Macaque monkey, killed his animals 12 to 14 days after the lesion. Mettler and Hanada (1942) state that in mammals cut myelinated fibres become "osmium susceptible" not earlier than the tenth day, that good results are secured after three weeks, and acceptable sections can be obtained as long as five weeks after the lesion. Strong and Elwyn (1943), with respect to human anatomy, state that the proper stage of degeneration for the use of the Marchi method is one to three weeks after injury. Brodal (1948) states that the changes in degenerating myelin giving rise to the characteristic appearances seen in the Marchi method reach their maximum 14 to 20 days after injury. Glees (1943), however, makes the interesting observation from work on cats and rabbits that Marchi granules could still be seen at the end of one year, although they were then transformed into a very fine, dust-like deposit. He remarks on the probability that the slowness of removal of the degeneration products has not been fully realized, and concludes that this retardation might profitably be used in the study of comparatively long-standing lesions.

Although Hurst (1925), studying the lipoids in neuronic degeneration, obtained staining with osmic acid up to six months after the lesion, and other workers (Kernohan and Woltman, 1929) used this method in lesions of indefinite duration to demonstrate that active degeneration was in process, the value of the Marchi method for tracing degenerating tracts in human material, in which lesions occurred six to 12 months before death, does not seem to have been generally realized. It is probable that observations made regarding the limits of the Marchi 


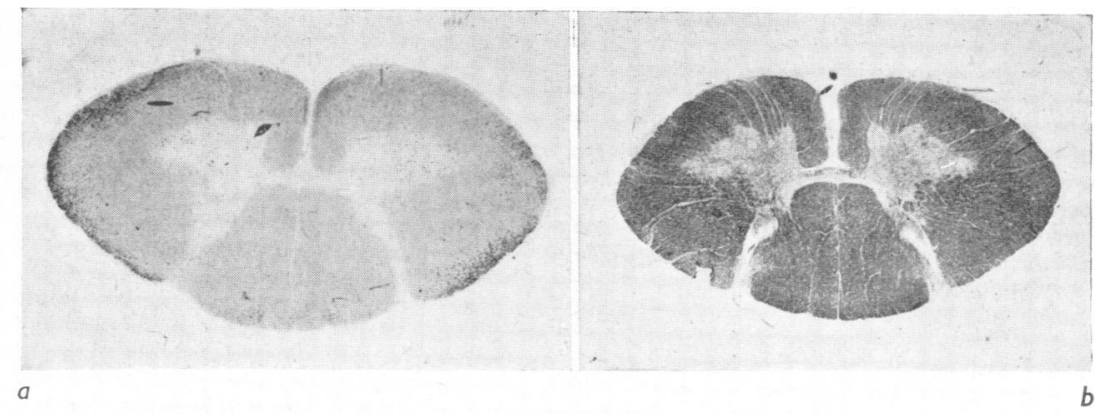

CASE 1
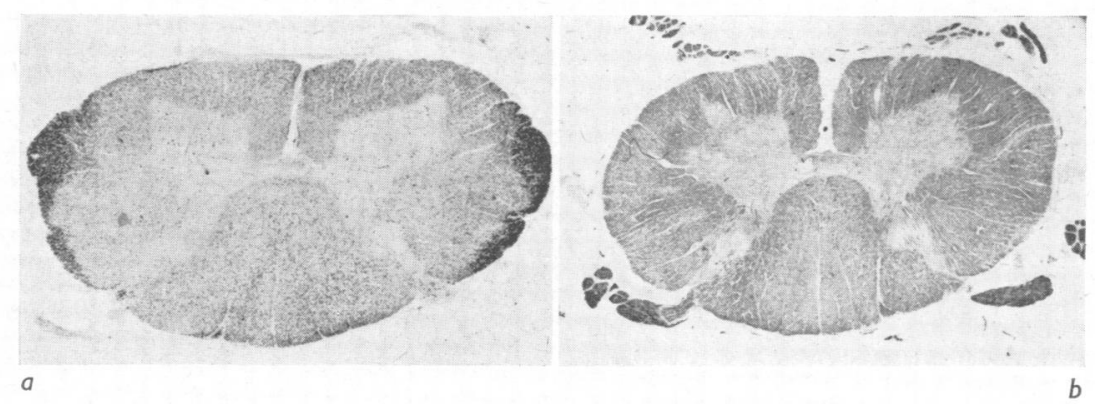

CASE 2

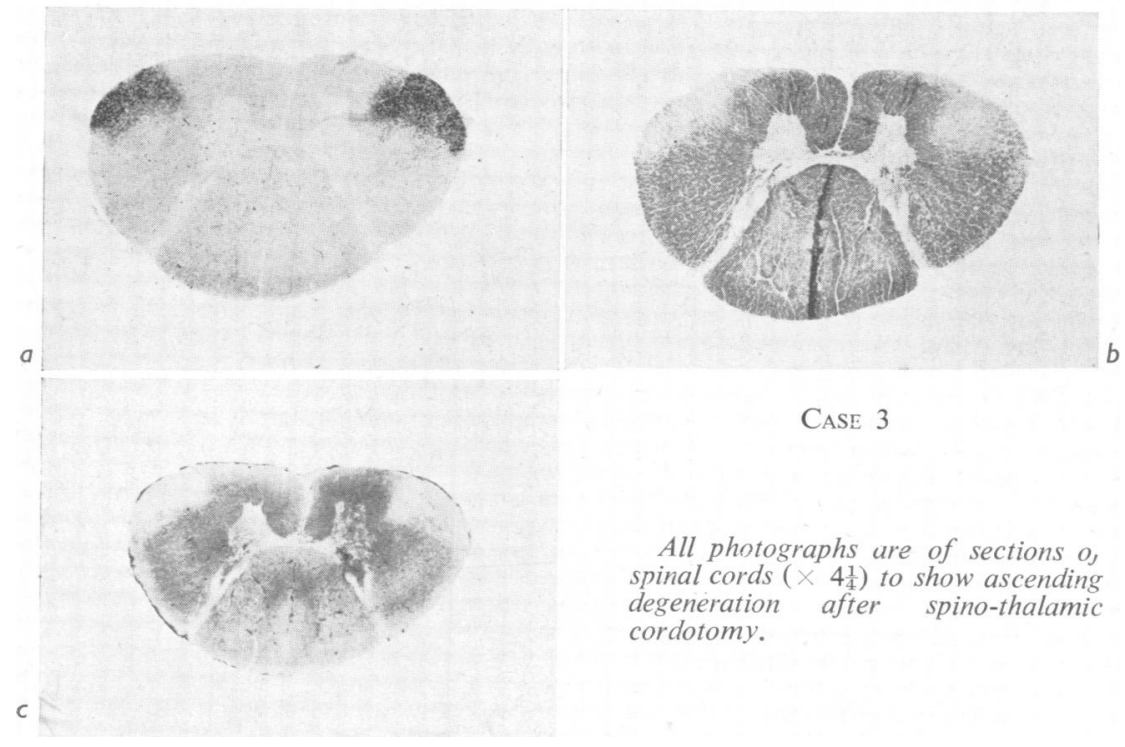

FIG. 1

In each case the methods of staining were as follows : Marchi in $a$, Weigert Pal in $b$, except for cases $1 b$ and $2 b$, which are stained by Loyez' method. Case $3 c$ is stained by Gros' silver method. The sections prepared by the Marchi method show the degenerating fibres stained black. The control preparations (Loyez and Weigert Pal) show the degenerating fibres as pale unstained areas, except in cases 1 and 2 where the interval between operation and death was too short for the degenerating fibres to be shown up by these stains.

The intervals between operation and death were as follows: case $1: 23$ days; case $2: 42$ days; case 3 : 123 days; case $4: 154$ days; case $5: 159$ days; case $6: 313$ days; case $7: 400$ days. 


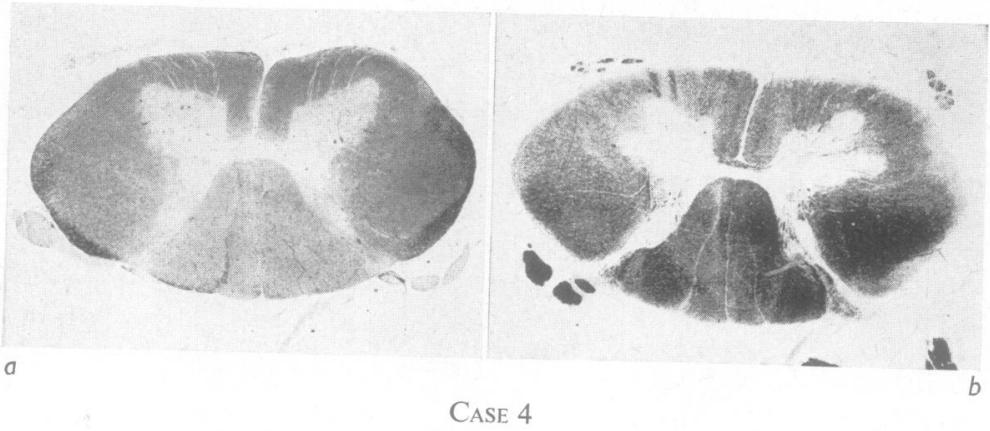

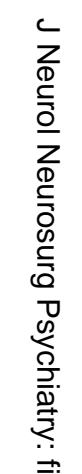

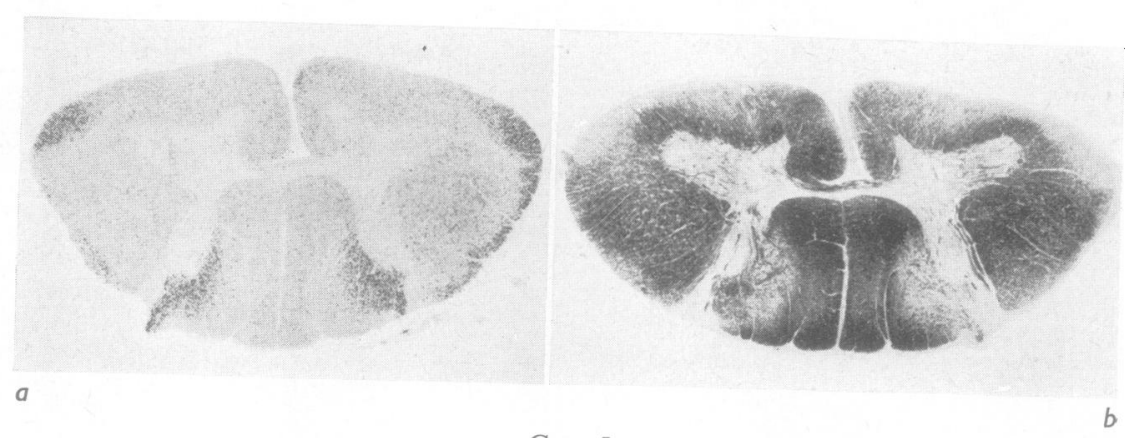

CASe 5

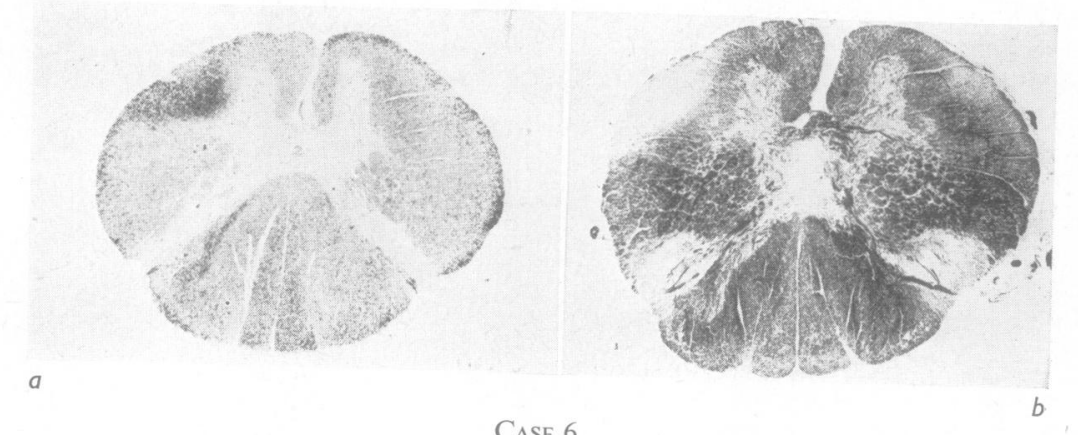

CASe 6

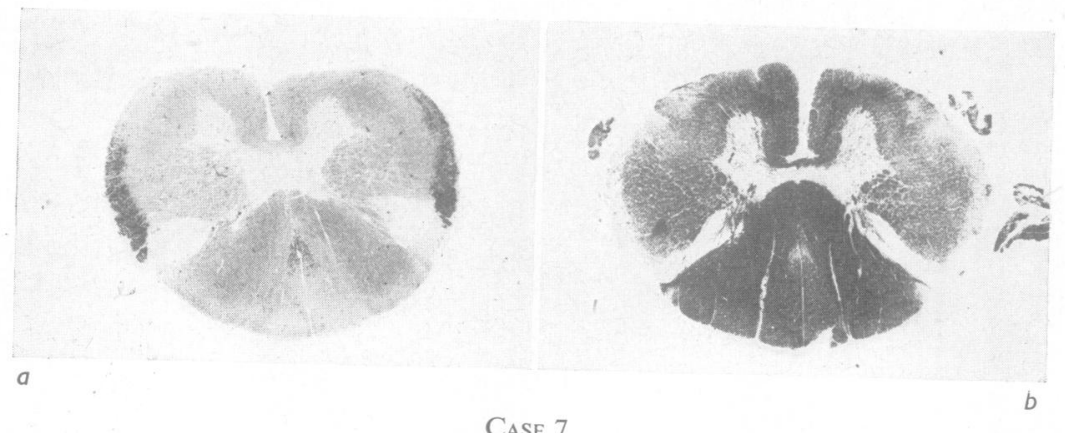

CASE 7

FIG. 2 
method have been made on experimental animal material, and applied to human material.

The cases shown here are taken from a series in which the operation of spino-thalamic cordotomy was performed. The interval between the division of the tract, and the death of the patient was therefore known. There was no involvement of the central nervous system before operation.

The method of staining the tissue was the SwankDavenport technique, modified by Glees (1943); the sections were prepared by the celloidin method. Photographs of these Marchi preparations are shown in Figs. 1 and 2. It is to be noted that they are from sections made as long as four and a half years ago. In fresh sections the contrast between normal and degenerating myelin is more striking. In all cases except case 3 the operation was performed at the midthoracic level; sections shown here are from cervical segments, so that degeneration products in tracts at a considerable distance from the lesion may be seen. In case 3 , the sections are from the next segment cranial to the lesion. In all the cases, except cases 1 and 2, Weigert Pal preparations from sections adjacent to the area studied by the Marchi technique, have been photographed and are given for comparison (area of degeneration unstained). In cases 1 and 2, Weigert Pal sections were not available, and Loyez' myelin stain preparations have been given in their place. In case 3, a section stained by Gros' silver method is also photographed to demonstrate the similarity of the shape of the degenerated area shown by the three different methods.

The intervals between operation and death are as follows : case 1 : 23 days; case 2 : 42 days; case $3: 123$ days; case $4: 154$ days ; case 5: 159 days ; case $6: 313$ days ; case $7: 400$ days.

The cases shown here illustrate the clear positive Marchi staining present at intervals up to 13 months after the lesion. It is not possible with the longer intervals to be sure that the entire extent of the degeneration is shown in the Marchi preparations, but even at these long intervals a clear indication of the tracts involved is obtainable, and, particularly in the brain, small groups of black degenerating fibres are more easily seen than are the pale areas in a Weigert Pal preparation. The two methods of staining may then be used in conjunction with each other, in topographical investigations in human work, after fairly long intervals.

It seems probable that the optimum time, and the limits of use of the Marchi method, vary in different species. There may well be a different rate of degeneration not only from species to species, but also between different members of the same species, and possibly in different tracts in the same individual. One realizes that there is an optimum period in degeneration when the maximal amount of degenerating myelin stains by the Marchi method. After this period of optimum staining there is likely to be a period lasting some months when staining adequate for tracing tracts can still be obtained.

\section{Summary}

Evidence is given showing that Marchi staining is useful in following degenerating nerve tracts in human tissue at intervals up to 13 months after division of the tracts.

My thanks are due to Dr. E. A. Carmichael for his help and criticism, and to Mrs. J. A. Mills for her ungrudging assistance in the technical work and photography.

\section{REFERENCES}

Allen, W. F. (1923). J. comp. Neurol., 35, 171.

Brodal, A. (1948). " Neurological Anatomy in Relation to Clinical Medicine", p. 8. Oxford.

Clark, W. E. Le Gros (1936). J. Anat., Lond., 71, 7.

Glees, P. (1943). Brain, 66, 229.

Hurst, E. W. (1925). Ibid., 48, 1.

Kernohan, J. W., and Woltman, H. W. (1929). Arch. Neurol. Psychiat., Chicago, 21, 274.

Kingsbury, B. F., and Johannsen, O. A. (1927). " Histological Technique," p. 89. New York.

Mettler, F. A., and Hanada, R. E. (1942). Stain Tech., $17,111$.

Poljak, S. (1933). J. comp. Neurol., 57, 541.

Strong, O. S., and Elwyn, A. (1943). "Human Neuroanatomy," p. 42. Baltimore.

Swank, R. L., and Davenport, H. A. (1934). Stain Tech., 9, 11. 